\title{
TRADUÇÃO COMO PRÁTICA E CRÍTICA DE UMA RAZÃO RELACIONAL ${ }^{1}$
}

\author{
Mauricio Mendonça Cardozo* \\ Universidade Federal do Paraná/CNPq
}

\begin{abstract}
Resumo: Tendo por base uma perspectiva relacional de compreensão da tradução, este residiria no fato de que a tradução, entendida como fenômeno ou como prática social, realiza uma possibilidade de construção da relação com o outro ao mesmo tempo em que dramatiza a razão (a ordem, a lógica, a dinâmica) que instaura essa possibilidade.
\end{abstract}

Palavras-chave: Tradução e alteridade. Relação. Razão relacional. Poiesis.

\section{TRANSLATION AS PRACTICE AND CRITIQUE OF A RELATIONAL REASON}

\begin{abstract}
Based on a relational perspective of understanding translation, this paper aims at discussing the hypothesis according to which its relational singularity lies in the fact that translation, understood as a phenomenon or as a social practice, performs the construction of a relation to the other while dramatizes the reason (the order, the logic, the dynamics) which establishes this possibility.
\end{abstract}

Keywords: Translation and Alterity. Relation. Relational reason. Poiesis

\footnotetext{
*Formação em Letras (Língua e Literatura Alemã), Universidade Federal do Paraná. Mestrado em Letras (Língua e Literatura Alemã), Universidade de São Paulo. Doutorado em Letras (Língua e Literatura Alemã), Universidade de São Paulo e Universidade de Leipzig. Pós-Doutorado em Teoria da Tradução, Pontifícia Universidade Católica do Rio de Janeiro. Pós-Doutorado em Estudos da Tradução, Johannes Gutenberg-Universität Mainz e Univeristé de Strasbourg. Professor associado da Universidade Federal do Paraná. Curitiba, Paraná, Brasil. E-mail: maumeluco@uol.com.br
} 
Or, la traduction occupe ici une place ambiguë. D’une part, elle se plie à cette injoction appropriatrice et réductrice, elle se constitue comme l'un de ses agents. [...] Mais d'autre part, la visée étique du traduire s'oppose par nature à cette injonction : l'essence de la traduction est d'être overture, dialogue, métissage, décentrement. Elle est mise en rapport, ou elle n'est rien.

Antoine Berman ${ }^{2}$

Both the theory and praxis of critique demonstrate that, from now on, critique absolutely needs to rest on some principle other than that of the ontology of the Other and the Same: it needs an ontology of being-with-one-another. [...] To put it in Kantian terms, if pure reason is practical by itself (and not by reference to and according to any reverence for some transcendental norm), this is because it is essentially "common reason", which means the "with" as reason, as foundation.

Jean-Luc Nancy ${ }^{3}$

A quem se concede o privilégio de falar de tradução? A nós, especialistas - pressupondo-se a possibilidade de definir com alguma precisão e de maneira inequívoca o que seja e, consequentemente, quem seja um especialista em tradução? Aos outros, pensadores de áreas afins, mas interessados pela tradução - pressupondo-se que o que os outros chamam de tradução se aproxime minimamente daquilo que nós, especialistas, nomeamos como tradução e, portanto, que aquilo que nós referimos por tradução seja noção minimamente inequívoca mesmo nos limites da comunidade dos chamados especialistas, mesmo entre os que, aqui, subscrevem essa rubrica de um nós?

A quem se concede o privilégio de falar com propriedade sobre tradução - pressupondo-se que a tradução possa ser objeto de propriedade, que se permita ser apropriada, circunscrita como própria nos domínios de uma prática profissional? Tradutores e intérpretes, profissionais dessa prática milenar? Para tanto, seria necessário pressupor critérios mínimos que definem quem é e quem não é 
um profissional da tradução. Seria o portador de um diploma de nível superior? O prático sem-formação específica (mas que atua há décadas na área)? Aquele que independentemente de experiência ou formação simplesmente vive de tradução, ou seja, aquele, cuja atividade principal é traduzir? Ou qualquer pessoa que possua alguma experiência de tradução, que tenha vivido seu episódio íntimo e pessoal de um fazer tradutório?

Não há que se questionar a evidência de que a tradução seja o nome com que se assina uma prática discursiva de caráter tanto eventual, diletante, quanto profissional. Não há que se questionar a evidência de que a tradução seja o nome com que se assina o objeto de investigação e uma prática de formação num campo disciplinar hoje conhecido como os Estudos da Tradução. Todavia, a tradução pode ser um instrumento e uma questão tanto num círculo mais restrito de especialistas quanto num contexto mais heterogêneo, com os outros, entre os outros, ditos leigos. Tradução é uma prática, mas é também um tema corrente, recorrente. Tradução é experiência e, como tal, é parte da nossa vida e da vida dos outros. Tradução rende uma conversa. A tradução é muitas coisas. A tradução tem muitos lugares.

Sem pretender aqui o exercício de resposta às perguntas que abrem esta reflexão, o simples fato de ser possível pressupor para cada uma delas uma variedade tão ampla de respostas, coloca-nos diante da evidência de que a tradução, em seus tantos lugares, é apenas mais uma dentre tantas outras práticas humanas que se instauram numa ordem discursiva e que, como tal, é atravessada pelas várias dimensões que, juntas, compõem e fundam a complexidade da própria condição humana. É nesse sentido que podemos dizer que a tradução acontece tanto como instrumento, como prática trivial ou profissional de nosso dia a dia, em geral numa dimensão mais evidentemente linguística, quanto como uma questão, atravessada pela mesma complexidade e densidade de questões discutidas e problematizadas nos diversos campos das Humanidades.

A tradução é sabidamente uma prática ancestral e, seja como instrumento, seja como questão, sempre despertou o interesse de 
pensadores de várias áreas do saber, não se restringindo, portanto, a um domínio exclusivamente profissional da tradução. A partir da década de 70 do século XX, com o início do processo de institucionalização da pesquisa em tradução e da formação de tradutores, 0 fenômeno tradutório passaria a figurar como objeto central de um campo de pesquisa bastante amplo e heterogêneo, hoje plenamente estabelecido (cf. CARDOZO, 2010). No entanto, a despeito de sua imensa força congregadora, que lograria aproximar perspectivas e interesses tão diversos, a circunscrição desse campo de pesquisa não minimizaria o incessante interesse de outras áreas de especialidade pelo fenômeno tradutório. Da antropologia à psicanálise, da sociologia à filosofia da ciência, a tradução continua, hoje, despertando a curiosidade de especialistas dos mais variados campos do saber, que se servem de certa compreensão desse fenômeno para os fins de suas próprias reflexões. Parte-se aqui da hipótese de que boa parte desse interesse remonte a uma percepção da tradução como caso paradigmático de prática social e discursiva de relação com o outro. Não no sentido de que a tradução seja mais relacional que outras práticas sociais e discursivas, mas sim, no sentido de que, como prática social e discursiva, a tradução seria capaz de explicitar, de maneira singular, diferentes aspectos da complexidade de uma relação em construção, de uma poiesis da relação. ${ }^{4}$

Mas se, por um lado, sua natureza relacional pode justificar parte desse interesse de outras áreas, como a filosofia, a antropologia e a psicanálise, por outro lado, é de se pensar que o próprio campo de pesquisa teórica em tradução, assumindo a natureza relacional de seu objeto, também pudesse se beneficiar de um diálogo com essas outras áreas, especialmente com a obra de pensadores que, a seu modo e no horizonte de suas reflexões, construíram uma espécie de pensamento contemporâneo sobre a relação. No entanto, como aparentemente sempre estivemos mais preocupados com a institucionalização de nossa própria área do que com ganhos epistemológicos - de outras áreas - de que nos pudéssemos valer, esforços nesse sentido ainda são bastante raros no campo dos Estudos da Tradução. Em seus casos de exceção, a questão da relação, 
catalisada na figura da tradução, surgiria como um possível elemento de aproximação desses vários interesses, práticas e saberes, dentro e fora da área dos Estudos da Tradução.

Todavia, ainda que a tradução possa ser tomada como exemplo paradigmático de prática relacional, ${ }^{5}$ é preciso perguntar: isso não seria óbvio?

Não parece haver grande novidade em supor que a tradução, mesmo em suas acepções mais disseminadas 7 como passagem, transferência, transporte, transposição, etc. $\square$, implique num movimento em que o tradutor constrói uma relação. Não parece haver grande novidade em supor que, na tradução, o tradutor relaciona línguas, textos, culturas e, portanto, diferentes sujeitos, diferentes tempos, diferentes contextos políticos, sociais, ideológicos, diferentes tradições editoriais, literárias, tradutórias, etc. Afinal, não haveria desde sempre certa noção de relação pressuposta aos mais variados discursos sobre a tradução ao longo de toda a história, ainda que essa noção apenas muito raramente tenha se explicitado como tal, nominalmente? Não seria, por exemplo, a tradicional noção de equivalência entre texto original e traduzido uma espécie de quintessência tradutória da ideia de tradução como relação nesse caso, como uma relação bem específica, como uma relação de equivalência?

Difícil não responder afirmativamente a essas perguntas, na medida em que associar a tradução a uma noção de relação parece mesmo beirar a obviedade. Afinal, como pensar a tradução, seja como prática, seja como fenômeno, sem nos valermos de alguma figura relacional? A obviedade, porém, também tem suas armadilhas.

Se por um lado essa perspectiva parece de fato não se bastar, já que a simples compreensão da tradução sob o signo da relação não se ofereceria como grande promessa de novidade para a discussão da prática ou do fenômeno tradutório, por outro lado, a tematização dessa natureza relacional e a problematização da própria noção de relação está longe de ser uma questão comum, ao menos na forma mais explícita da pergunta: mas o que é, enfim, essa relação, que nos parece assim tão óbvia na tradução? 
Ao que tudo indica, estamos distantes de termos uma resposta óbvia para essa pergunta, seja no campo mais geral das Humanidades, seja no campo específico dos Estudos da Tradução. É bastante óbvio pensar a tradução a partir de alguma forma de relação, mas a força dessa obviedade talvez nos impeça de reconhecer imediatamente na relação uma questão, tanto menos uma questão tradutória, ainda que ela assim se imponha.

Como exemplo do efeito dessa obviedade no campo mais amplo das Humanidades, vale lembrar a observação que Jean-Luc Nancy faria, no contexto de uma mesa-redonda sobre amor e comunidade, realizada em 2001, na Suíça, e que retoma uma questão discutida mais centralmente em Être singulier pluriel, de 1996. Segundo o filósofo, causa-lhe estranheza o fato de que o Heidegger de Ser e Tempo, tão pronunciadamente minucioso em suas longas discussões conceituais, não colocaria em discussão o termo mit (with, com) da noção de Mit-sein (Being-with, Ser-com). Para Nancy, o detalhe é muito significativo, na medida em que seria sintomático do fato de que, para Heidegger, assim como para a filosofia em geral, o com (como signo, como operador e como lugar da relação) não constituiria propriamente uma categoria ou, quando muito, por sua obviedade, constituiria uma categoria vazia. Para Nancy, como já anuncia a epígrafe deste trabalho, é preciso problematizar esse "with", esse "com", já que: “With' is neither mediate nor immediate. [...] 'With' neither goes from the same to the other, nor from the same to the same, nor from the other to the other. In a certain sense, the 'with' does not 'go' anywhere; it does not constitute a process" (NANCY, 2000, p. 98). E problematizar o "com" significa, também, repensar a ordem relacional implicada na obviedade desse "com" - opaco na medida extrema de sua transparência.

Essa aparente obviedade, entretanto, não parece se fundar numa compreensão inequívoca do que seja a relação, já que empregamos esse significante comumente em uma variedade imensa de sentidos.

Há uma noção de relação como operador lógico-matemático: como a relação entre dois números ou duas grandezas, a relação de equivalência, a relação de ordem, a relação (entre elementos de 
diferentes conjuntos) que funda uma função, a relação de igualdade (entre expressões matemáticas) que funda uma equação. Há uma noção de relação como um operador linguístico: como as relações sintagmáticas (transitividade, regência), as relações associativas ou paradigmáticas (sinonímia, antonímia, metonímia), enfim, qualquer tipo de interdependência entre elementos linguísticos. Há uma noção de relação que resulta da comparação: como a relação de identidade, a relação de diferença, a relação de semelhança, ou de parecença, enfim, quando se diz que uma coisa tem ou não tem relação com a outra. Há também a noção de relação como princípio estruturador de um sistema: como nas relações econômicas (de produção, circulação), nas relações de mercado (lei da oferta e procura) e na ideia de relação como troca, como relação comercial (importação, exportação). É bastante forte, ainda, a noção de relação como vínculo, no sentido de pertencimento: como no caso da relação de parentesco, de familiaridade, de nacionalidade, de etnia, de gênero, enfim, nas relações constitutivas da percepção de pertencimento a uma comunidade, a um grupo. E há ainda a noção de relação como o desafio do face a face, no sentido da convivência num espaço comum: ora como delimitação desses círculos de convivência, como na relação de amizade, na relação de trabalho, na relação de negócios, nas relações diplomáticas; ora como hierarquização das relações nesse espaço, como na relação de submissão, na relação de domínio; ora como expressão da natureza dessas relações de convivência, como na relação de conflito ou de litígio (na guerra), na relação afetuosa e na relação sexual (no amor e na amizade), na relação de transferência (no sentido psicanalítico), etc.

Mas de que noção de relação estamos falando exatamente quando pensamos na tradução como uma prática relacional? É provável que a noção de relação que funda e instrui cada uma das tantas compreensões possíveis de tradução defina-se a partir da articulação complexa de algumas dessas acepções mencionadas acima, entre outras. Seja como for, a simples evidência de que a questão da relação não se apresenta como noção inequívoca obriga-nos a 
questionar sua obviedade. E questionar sua obviedade no contexto de uma reflexão que se funda numa compreensão relacional da tradução, implica em não poder ignorar a amplitude e a complexidade das questões levantadas no contexto de um pensamento contemporâneo sobre a relação.

Como exemplos de noções fundadoras disto que aqui se circunscreve como um pensamento contemporâneo sobre a relação vale destacar: uma noção de liminaridade como condição dinâmica da relação, que pode ser discutida a partir de figuras como a da finitude e a da abertura, nos termos em que são tematizadas nas obras de Martin Buber, especialmente em Eu e Tu (2003), de Emmanuel Levinas, especialmente em Totalidade e infinito (2000) e em Le temps et l'autre (1983), de Jean-Luc Nancy, especialmente em Être singulier pluriel (1996) e de Jacques Derrida, especialmente em On touching: Jean-Luc Nancy (2005); a noção de tempo e temporalidade, como condição acontecimental da relação, que pode ser discutida a partir de figuras como a da imanência (nos domínios de chronos, da duração, da extensão) e a da iminência (nos domínios de kairós, da ocasião, do instante, da agoridade), nos termos em que surgem no contexto de reflexões clássicas (e de alguns de seus desdobramentos contemporâneos) em torno da questão do tempo (de Agostinho a Benjamin, de Husserl a Bergson e Bachelard, de Heidegger a Ricoeur, de Nietzsche a Onfray e Comte-Sponville); a noção de espacialidade, como condição ética da relação, que pode ser discutida tanto a partir de sua figuração clássica como espaço relacional de convivência ou como espaço de inscrição do ethos na physis, quanto a partir do desafio do comum, da comunidade e do caráter singular plural desse espaço de convivência, nos termos da reflexão de Jean-Luc Nancy, por exemplo, em La communauté désoeuvrée (1982; cf. também NANCY 1996, 2001, 2010); e a noção de incondicionalidade, como condição ontológica da relação, nos termos em que essa noção figura na obra de Jacques Derrida, em especial em suas reflexões sobre a figura do perdão, em $O$ que é uma tradução relevante (DERRIDA, 2000) e sobre a figura da hospitalidade, em Adeus a Emmanuel Lévinas (DERRIDA, 2004) 
e em Anne Dufourmantelle convida Jacques Derrida a falar da hospitalidade (DERRIDA; DUFOURMANTELLE, 2003) ${ }^{6}$.

Assumir uma compreensão da tradução como prática relacional implicaria, portanto, em pensar que diferentes concepções de tradução se fundam em modos diferentes de compreender o que seja a relação, o que seja a não relação e o que não seja relação. Implicaria em pensar que diferentes compreensões de tradução se fundam em modos diferentes de compreender o que seja a ordem, a lógica e a dinâmica em que se instaura a relação. Enfim, assumir uma compreensão relacional da tradução implicaria em assumir que toda concepção de tradução se funda em (ou é fundante de) uma determinada razão relacional $\square$ razão, aqui, no sentido do conjunto de pressupostos que fundam a ordem, a lógica e a dinâmica em que se inscreve uma prática tradutória ou determinada compreensão de tradução. Portanto, entenda-se a noção de razão relacional, aqui, no sentido do conjunto de pressupostos (efetivos, mas não necessariamente delimitados; ativos, mas não necessariamente conscientes) que determina os limites e as possibilidades de uma prática de tradução ou de uma compreensão de tradução. Entenda-se a noção de razão relacional no sentido do conjunto de pressupostos que determina uma compreensão do que seja o eu e o outro da tradução, bem como do que seja e de como se dê a relação que aí se estabelece.

Trata-se aqui, em última análise, de colocar em pauta, como questão no campo teórico dos Estudos da Tradução, as diferentes razões relacionais que fundam as mais variadas compreensões de tradução. ${ }^{7}$ E de definir seu foco, na medida em que entendemos a singularidade relacional da tradução nos seguintes termos: a tradução é uma das práticas que performa a relação com o outro, mas é também a prática que, nesse mesmo gesto, dramatiza essa relação, esse confronto, esse enfrentamento em toda a extensão de suas possibilidades e impossibilidades. Nesse movimento, nesse gesto, nesse esforço de relação com o outro, a tradução se realiza, mas também põe a nu a razão relacional que a instaura. Em outras palavras: além de articular uma relação (tradutória) com o outro 
a partir de uma ordem, de uma lógica e de uma dinâmica que são fundantes de uma determinada razão relacional, o ato de tradução, no enfrentamento da relação, na relação como enfrentamento, também explicita a razão relacional em que se funda.

Nesse sentido, por exemplo, o texto traduzido é produto de um movimento fundado numa razão relacional, mas, ao mesmo tempo, como produto dessa relação estabelecida com o original, explicita a razão relacional que lhe deu origem. Explicita a compreensão particular de uma dinâmica relacional, do que seria, no contexto dessa relação tradutória, em particular, o colocar em relação: como um movimento mecânico, ascético, automático; como um esforço, um trabalho, uma construção ou $\mathrm{p}$ para retomar aqui a primeira epígrafe deste trabalho - como um mise en rapport bermaniano, que é tanto redução quanto abertura, apropriação quanto descentramento. Explicita uma compreensão da ordem relacional, do estatuto ético e ontológico que funda uma compreensão do eu e do outro da relação. Enfim, explicita o que significa para o eu e para o outro estar numa relação tradutória, bem como o valor que o eu e o outro assumem na economia dessa relação.

É nesse sentido que podemos dizer que a tradução, seja como instrumento, seja como questão, manifesta-se, a um só tempo, não somente como prática, mas também como crítica de uma determinada razão relacional.

A tradução chega e diz. Mas ao dizer, e por dizer, coloca também a própria possibilidade de seu dito em questão. Assim como o estrangeiro de Derrida, em sua reflexão sobre a hospitalidade (DERRIDA; DUFOURMANTELLE, 2003), a tradução sempre chega como questão.

É nesse sentido que a relação tradutória se projeta como sobrevivência, como pervivência de uma obra, mas também performa, necessariamente, sua metamorfose: a relação tradutória, a um só tempo, como vida e como morte. É nesse sentido que a tradução, seguindo certa lógica do mesmo, também coloca em questão essa lógica, pois, se por um lado, por definição, é da natureza da tradução apresentar-se como um mesmo texto, uma mesma obra, a 
tradução também explicita, nesse gesto - e justamente por não ser mero reflexo, mas constituir-se como gesto singular que produz um texto que é outro -, a tradução explicita aí sua inexorável alteridade e, nisso, sua condição de, a um só tempo, ser o mesmo E ser outro. Ou seja, se a tradução, como prática relacional, opera numa certa economia do valor do mesmo, é preciso levar em conta, também, que ela coloca o princípio articulador dessa equi-valência em questão, que ela performa a sua crítica.

É nesse sentido que a possibilidade da tradução dramatiza sua impossibilidade. A tradução é impossível, mas acontece! E por acontecer, na possibilidade desse acontecer, põe em questão sua impossibilidade (cf. SELIGMANN-SILVA, 2005), faz a crítica da impossibilidade, daquilo que se expõe como limite do possível e do que se impõe como alargamento do impossível.

É também como prática e crítica relacional que, bejaminianamente falando, a tradução, como esforço pós-babélico, aponta para uma unidade arquetípica, ao mesmo tempo em que necessariamente dramatiza o despertar de um sonho de unidade (BENJAMIN, 1994), para a condição fragmentária e heterogênea das línguas e na língua (DERRIDA, 2006).

É nesse sentido que a tradução, como prática que tem por horizonte ideal o acesso ao outro em si, dramatiza também a crítica dessa possibilidade de acesso, uma vez que se funda inexoravelmente numa força transformadora: o enfrentamento do outro é também um enfrentamento de si mesmo e é nessa exata medida que a relação com o outro nos transforma (LEVINAS, 1983, p.63, entre outras). A tradução performa os limites do face a face e, justamente nisso, faz também a crítica de nós mesmos. A formulação, em sua dimensão mais abstrata, encontra grande produtividade na filosofia, exemplarmente na obra de Emmanuel Levinas. Mas é também dessa força transformadora da relação que se valem poetas, críticos e tradutores ao performarem um movimento de tradução do outro que é, a um só tempo, instrumento crítico daquilo que lhes é mais próprio. Podemos encontrar diferentes exemplos disso, tanto entre os poetas-críticos-tradutores da primeira geração romântica alemã 
quanto na obra poética, crítica e tradutória de Ezra Pound e de figuras como Haroldo de Campos e Augusto de Campos.

É também nesse sentido que a tradução opera numa certa lógica do entre (por articular-se sempre como relação entre autor e leitor, entre línguas, entre culturas, etc.), mas também performa a crítica dessa lógica. E faz isso na medida em que se explicita como experiência que sempre tem lugar (numa determinada língua, numa determinada cultura de chegada), que se dá num lugar, ainda que atravessado de origens. Ou seja, se por um lado a tradução se funda numa experiência intensa do entre, numa forma radical de hifenização, não permite que esse entre se acomode simplesmente como outra forma de se dizer que a tradução não tem lugar, em parte alguma. A tradução opera na lógica das fronteiras, ao mesmo tempo em que questiona, faz a crítica da lógica que as instauram.

E é nesse sentido, ainda, que a tradução opera na lógica do dito (traduz-se o que se disse, diz-se de novo o que foi dito), mas também performa uma crítica a essa lógica, na medida em que dramatiza o que na tradução também se diz quando se cala. Ao enfrentar o double bind do pharmakon (DERRIDA, 1991), traduzindo-o por veneno, a tradução diz o veneno, mas também fala dessa opção, dessa escolha, diz que nessa opção algo necessariamente se silencia, uma outra opção possível (o remédio, a cura), que não foi a escolhida. Ao dizer-se veneno, a tradução também dá voz ao que nela silencia, mas não se cala.

Por fim, é nesse sentido que o esforço de estabelecimento de uma área, seja como domínio ou espaço de relação, que o esforço de institucionalização de um campo disciplinar, de uma disciplina centrada no significante tradução e nos diferentes objetos que esse nome assina - é nesse sentido que tal esforço de construção de uma unidade, de uma comunidade constitui-se, também, como crítica das noções de disciplinaridade, de fronteira disciplinar, de inter-, multi-, transdisciplinaridade, da noção de objeto, da noção de especificidade, etc..

É ao dizer a tradução como prática relacional, mas dando ouvidos a sua dimensão de crítica de uma razão relacional, que se 
impõe o desafio de pensar, de continuarmos pensando, o que fizemos, fazemos e continuaremos fazendo dentro e fora do campo dos Estudos da Tradução.

\section{Notas}

1. Uma versão preliminar deste artigo foi apresentada no 9. Deutscher Lusitanistentag / IX. Congresso Alemão de Lusitanistas, em Viena, em setembro de 2011, com apoio da CAPES.

2. BERMAN, 1984, p. 16, grifos do autor.

3. NANCY, 2000, p. 53, p.99, grifos do autor.

4. Esta perspectiva relacional de compreensão da tradução é diretamente tributária da reflexão do teórico francês Antoine Berman e, nesse sentido, indiretamente tributária de uma compreensão relacional da prática tradutória que remonta, no mínimo, ao contexto do pensamento romântico alemão e a alguns de seus precursores, como o filósofo Johann Gottfried von Herder. Vide também, a esse respeito: CARDOZO 2004, 2007, 2008, 2009a, 2009b.

5. Assumindo-se que esse traço relacional de sua natureza possa justificar parte do interesse que desperta em outras áreas e, consequentemente, que seria, no mínimo, muito curioso revisitar parte da história ocidental como uma história das práticas de relação e do pensamento sobre a relação com o outro. Para uma pequena síntese dessa perspectiva histórica do advento da questão da relação no contexto do pensamento ocidental moderno, vide, entre outros, CARDOZO, 2010.

6. Essa discussão, apenas brevemente sintetizada aqui, está em curso no contexto do projeto de pesquisa "Tradução como poiesis da relação: a questão do outro em tradução", que conta com o apoio do CNPq. 
7. Cabe aqui uma advertência: não se trata de empreender aqui uma crítica DA razão relacional, no sentido da busca por aprioris universalmente válidos para diferentes compreensões de tradução. Tampouco se trata, aqui, da defesa de UMA forma privilegiada de compreender (e exercitar) determinada compreensão da razão relacional, pressuposta como geral, genérica, universal. Trata-se, antes, de pensar que cada expressão (do pensamento e da prática) da tradução é fundada numa razão relacional e, portanto, de pensar a razão relacional como lógica, como ordem e como dinâmica fundante (velada ou consciente), implicada em toda e qualquer manifestação prática da tradução, bem como em cada forma de compreender o que seja tradução. Nesse sentido, ao presumir uma forma de compreender um outro, um eu e uma dinâmica relacional da prática da tradução, isso que chamamos aqui de uma razão relacional estabeleceria, a um só tempo, os limites e as possibilidades da tradução como prática relacional.

\section{Referências}

BENJAMIN, W. Die Aufgabe des Übersetzers. In: . Iluminationen. Frankfurt am Main: Suhrkamp, 1994. p. 50-62.

BERMAN, A. L'épreuve de l'étranger : Culture et traduction dans l'Allemagne romantique. Paris: Gallimard, 1984.

BUBER, M. Eu e Tu. Tradução, introdução e notas Newton Aquiles von Zuben. 6. ed. revista. São Paulo: Centauro, 2003.

CARDOZO, M. M. Os Estudos da Tradução no contexto das Humanidades: praxis tradutória como experiência positiva dos limites da relação com o outro. In: GONÇALVES, A. B. et al. Literatura, Crítica e Cultura III. Juiz de Fora: Editora UFJF, 2010. p.143-60.

. O significado da diferença: a dimensão crítica da noção de projeto de tradução literária. Tradução e Comunicação: Revista brasileira de tradutores, Valinhos, v. 18, p. 101-17, 2009a. 
. Tradução e o trabalho de relação: notas para uma poiética da tradução. In: PIETROLUONGO, M. A. (Org.). O trabalho da tradução. Rio de Janeiro: Ed. ContraCapa, 2009b, v. 12. p. 181-188.

. Tradução, apropriação e o desafio ético da relação. In: OLIVEIRA, Maria Clara Castellões de; LAGE, Verônica Lucy Coutinho. (Org.). Literatura, crítica, cultura I. 1. ed. Juiz de Fora: Editora UFJF, 2008. p. 179-90.

. Ilóquio ou por uma mecânica ética da tradução. Tradução em Revista, Rio de Janeiro, v. 04, p. 01-21, 2007.

. Solidão e Encontro: prática e espaço da Crítica de Tradução Literária. Tese de doutorado em Língua e Literatura Alemã, Faculdade de Filosofia, Letras e Ciências Humanas, Universidade de São Paulo, São Paulo, 2004.

DERRIDA, J. A farmácia de Platão. Tradução Rogério da Costa. São Paulo: Iluminuras, 1991.

. O que é uma tradução relevante? Tradução Olivia Niemeyer Santos. In:

RODRIGUES, C. C.; SISCAR, M. (org.). Tradução, desconstrução e pós-modernidade. Alfa: Revista de Lingüística, São Paulo, v.44, n.esp., p.13-44, 2000.

Adeus a Emmanuel Lévinas. Tradução Fábio Landa. São Paulo: Perspectiva, 2004.

. On Touching: Jean-Luc Nancy, Tradução Christine Irizarry. Stanford: Stanford University Press, 2005.

. Torres de Babel. Tradução Junia Barreto. Belo Horizonte: Editora $\overline{\text { UFMG }}, 2006$.

DERRIDA, J.; DUFOURMANTELLE, A. Anne Dufourmantelle convida Jacques Derrida a falar da Hospitalidade. Tradução Antonio Romane. São Paulo: Escuta, 2003. 
LEVINAS, E. Le temps et l'autre. 9. ed. Paris: Quadrige-Puf, 1983.

. Totalidade e Infinito. Tradução José Pinto Ribeiro. Lisboa: Edições 70, 2000.

NANCY, J.-L. La communauté désoeuvrée. Paris: Christian Bourgois, 1982.

. Être singulier pluriel. Paris: Galilé, 1996.

. Being Singular Plural. Tradução Robert D. Richardson e Anne E. O’Byrne. Stanford: Stanford University Press, 2000.

. La Communauté affrontée. Paris: Editions Galilée, 2001.

. Identité: Fragments, franchises. Paris: Editions Galilée, 2010.

SELIGMANN-SILVA, M. "Filosofia da tradução - tradução de filosofia: o princípio da intraduzibilidade". In: O local da diferença: Ensaios sobre memória, arte, literatura e tradução. São Paulo: Editora 34, 2005. p. 167-88.

Recebido em: $12 / 02 / 2014$

Aceito em: 23/05/2014 